\title{
ESTROGENS IN TISSUES: UPTAKE FROM TKE PERIPHERAL CIRCULATION OR LOCAL PRODUCTION
}

J.H.H. Thijseen, * M.A. Blankenstein, W.R. Miller, † and A. Milewiczł

*Depurtunent of Endocrinology, Universily Hoepial, Cutharijnewingel 101, 3511 GV Utrecht, The Nectheriands;

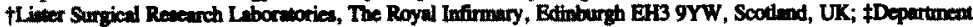
of Endocrimoloy, Modical Academy, Wroclaw, Polend

\section{ABSTRACT}

Because intratissue levels of estrogens may be more important for the understanding of the endocrine status of an organ than are peripheral plasma levels, the concentrations of eatrone and estradiol have been measured in normal and pathological breast and uterine specimens. Some breast tumors were collected in countries with differences in incidence and natural history of the disease. In other samples the subcellular distribution of the steroids was studied. Estrone levels did show much less variation than estradiol levels. Not related to estrogen receptors, estradiol levels were higher in uterine than in breast tissues. Also, the subcellular distribution observed could not be explained by changes in receptors. Malignant breast tumors of premenopausal and postmenopausal women contained similar amounts of estradiol. Unexplained large differences were found in the intratissue estradiol levels obtained in different countries.

\section{INTRODUCTION}

Steroid hormones, particularly estrogens, are thought to be involved in the etiology of breast and endometrial cancers (1). This involvement has not been supported by observations of consistent differences in plasma hormone levels in patients with and without these diseases $(2-6)$

Several other observations suggest the possibility that the intratissue concentration of steroid hormones may be more important with respect to the definition of the endocrine status of an organ than the peripheral blood levels of these hormones. This possibility is based on : 
(a) Higher steroid concentrations exist in tissues than in blood (710).

(b) No linear relations exist between tissue and plasma levels of estrogens $(10,11)$.

(c) The steroid content of the nuclei, the site where the hormonal effects ultimately are generated, is not simply related to the steroid and the receptor concentrations in tissues (11-15).

(d) Metabolic conversion of less active estrogens into more active forms occurs within the cells $(16)$.

As several investigators have demonstrated by in vitro studies (1722) that human breast tumors can produce estrogens, a study was done to measure the actual products of the aromatase enzyme activity, by measuring the estrogens in mammary tumors. These steroids exert their biological activity by binding to the estrogen receptor followed by tight binding of the steroid-receptor complex to the chromatin within the nucleus of the cells $(23,24)$. Therefore, an attempt was made not only to measure total concentrations but also to obtain information about the subcellular distribution of the estrogens. In comparison, the results obtained with similar techniques in uterine tissues will be presented.

If local factors are related to the incidence or the course of the disease in women, attention must be given to the large variations in the incidence of breast tumors in different countries. Therefore preliminary data will be presented based on studies of tissues from patients in countries with different incidence and natural history of breast cancer. 
MATERIALS AND METHODS

Malignant breast tumors were obtained from 52 patients in Utrecht, The Netherlands, 40 in Edinburgh, Scotland, and 15 in Wroclaw, Poland. All specimens were chilled immediately after operation, freed from fat and connective tissue, and stored at $-80^{\circ} \mathrm{C}$ or lower temperatures until analysis. All determinations were carried out in Utrecht by identical techniques, as described previously (25). The comparative study was done on concentrations in total tissue only.

In the Utrecht samples, subcellular distributions of estrogens were studied using the techniques as previously described (25). In addition, the homogeneity of the subcellular fractions was tested by measuring DNA, protein content, and lactic acid dehydrogenase (LDH) activity in the so-called cytosol and nuclear fractions. It was demonstrated that the nuclear fractions contained more than $95 \%$ of total DNA and less than 3\% of total LDH-activity of the tissues, whereas the cytosol contained more than $85 \%$ of extractable protein and more than $95 \%$ of the activity of the enzyme. Therefore, the crude fractions are reasonable representatives of the subcellular compartments.

Comparisons of the steroid concentrations in malignant samples could be made with 28 specimens of normal breast tissue obtained in Utrecht as well as with 27 samples of tissues with benign lesions. Additional$1 y$, from the Polish women 15 samples of non-breast adipose tissue were obtained. Normal specimens of uterine tissues were obtained from 20 premenopausal women during various periods of the menstrual cycle and from 53 postmenopausal women, as described previously $(9,10)$.

The estrogens were extracted from the tissues using acetone-ethanol; estrone and estradiol were separated and purified by Sephadex LH2O chromatography, and the amounts were measured using highly specific antisera. All results were corrected for losses during purification; the results were recalculated to concentrations in $\mathrm{pg} / \mathrm{g}$ wet weight of the tissue. Because the results obtained were not normally distributed, differences between groups were tested statistically by the twotailed wilcoxon rank-sum test or by Student's t-test after logarithmic transformations.

Mean values, when given, were obtained after log transformation of the data and conversion back to untransformed figures. These mean levels were in very good agreement with median values of the same group.

\section{RESULTS AND DISCUSSION}

\section{Estrogen Levels in Various Tissues}

In Table 1, the mean total concentrations of estrone and estradiol in tissue have been presented. Only mean levels have been given. The large variations observed in the levels have been described in the original publications, given under the references in the table. They will not be discussed in detail in this contribution. 
Table 1: Mean Endogenous Estrogen Levels in Human Uterine and Breast Tissues

\begin{tabular}{|c|c|c|c|c|}
\hline TISSUES & $\mathrm{n}^{\mathrm{a}}$ & $\begin{array}{l}\text { ESTRONE } \\
\mathrm{pg} / \mathrm{g} \text { tissue }\end{array}$ & $\begin{array}{l}\text { ESTRADIOL } \\
\text { pg/g tissue }\end{array}$ & REFERENCE \\
\hline \multicolumn{5}{|l|}{ UTERINE } \\
\hline \multicolumn{5}{|l|}{ Premenopausal } \\
\hline \multirow{4}{*}{$\begin{array}{ll}\text { endometrium foll.phase } & \text { secr.phase } \\
\text { myometrium } & \text { foll.phase } \\
& \text { secr.phase }\end{array}$} & 10 & 390 & 2,950 & 9 \\
\hline & 10 & 260 & 630 & 9 \\
\hline & 10 & 300 & 1,400 & 9 \\
\hline & 10 & 200 & 550 & 9 \\
\hline \multicolumn{5}{|l|}{ Postmenopausal } \\
\hline endometrium & 53 & 270 & 420 & 10 \\
\hline myometrium & 11 & 220 & 210 & 10 \\
\hline endometrial cancer & 13 & 180 & 350 & 26 \\
\hline \multicolumn{5}{|l|}{ BREAST TISSUES } \\
\hline \multicolumn{5}{|l|}{ Premenopausal } \\
\hline normal tissues & 22 & 305 & 120 & 11 \\
\hline benign disease & 14 & 270 & 120 & 11 \\
\hline malignant & 19 & 255 & 220 & 11 \\
\hline \multicolumn{5}{|l|}{ Postmenopausal } \\
\hline normal tissues & 6 & 105 & 85 & 11 \\
\hline benign disease & 13 & 215 & 85 & 11 \\
\hline malignant & 34 & 165 & 200 & 11 \\
\hline
\end{tabular}

$\mathrm{n}^{\mathrm{a}}$, number of samples studied.

From the results given, it is obvious that the intratissue estrone levels do show relatively little differences between various tissues. Because from a number of women endometrium as well as myometrium could be studied, the estrone levels in endometrium were found to be statistically significantly higher than in myometrium, based on paired observations. Furthermore, the estrone levels in breast tissues from premenopausal women were significantly higher than in tissues from 
postmenopausal women.

In contrast to the small variations observed for estrone, estradiol concentrations show much larger variations. The pre-ovulatory levels in both endometrium and myometrium are significantly higher than those during the secretory phase of the menstrual cycle. This difference has been attributed to the influence of progesterone on the behavior of the estradiol-receptor complex in uterine tissue (9). The levels in postmenopausal endometrial tissue are lower than those obtained in the follicular phase of women during the menstrual cycle. The tissue to plasma gradients for endometrium and myometrium, in the absence of progesterone, remain fairly constant with age.

Results for estradiol in breast tissue are completely different. Although plasma estradiol concentrations are much lower in postmenopausal women, the breast tissues contain very similar estradiol levels in both age groups. This shows that simple uptake of estradiol from the peripheral circulation can hardly explain the discrepancy between changes in plasma and tissue concentrations. It is more likely that local factors in the breast are responsible for the divergencies; local production of estradiol could well be involved.

The estrogen receptor level is not the main factor responsible for the tissue/plasma gradients of estradiol because no relation exists between estradiol and the receptor concentrations. Furthermore, estrone levels are higher than those of estradiol in many of the breast tissue specimens, regardless of the receptor status of the tissue.

Independent measurements of local intratissue concentrations of possible precursor steroids for aromatization of androstenedione or testosterone are not available, and therefore it is not possible to predict the influence of these substrates on the lacal formation of 
products. Another explanation for the results in breast tissues could be the existence of proteins with a lower binding affinity and a higher capacity for estrogens, the so-called nonspecific binding proteins, which could play a role in the uptake and concentrating mechanism in these tissues.

\section{Subcellular Distribution of Estrogens}

In addition to the total tissue concentrations, an attempt was made to study the subcellular distribution of both estrogens. Using the technique as described, the percentage of tissue estrone present in the nuclear fractions of endometrium and myometrium amounted to $45 \pm 3$ (SEM; $n=20)$. In the breast tissues only approx. $25 \pm 3 \%$ (SEM; $n=$ 105) of estrone was found in the nuclei, regardless of the histology of the sample and of the receptor concentration.

Also, the estradiol distribution shows differences between uterine and breast tissues. In all uterine samples, nuclear estradiol levels were higher than those in the cytosol, whereas in breast specimens the cytosol contained higher levels of estradiol. In the nuclei of endometrium and myometrium $68 \pm 4 \%$ (SEM; $n=26$ ) of estradiol was localized. The nuclear fractions of breast tissues contained $38 \pm 4 \%$ (SEM; $n=$ 108) of total estradiol, again regardless of histology of the sample. Receptor positive malignant specimens had higher percentages of estradiol in nuclear fractions than did receptor negative samples; however, no correlation between receptor levels and nuclear estradiol concentrations was calculated.

Therefore, the handling of estradiol seems to be different in uterine and breast tissues. Clearly the observed discrepancies cannot simply be explained by accumulation of estradiol in breast tissue because of binding to its receptor in the cells. In addition, local 
factors must be involved in the causation of the tissue concentrations; again, a difference in low affinity binding proteins in both tissues might be involved. No data are available on relations between the steroid levels in subcellular fractions and the activity of the local aromatase in breast cells.

\section{Estrogen Levels in Malignant Samples from Various Origins}

In a preliminary study, estrogen levels have been determined in specimens obtained from three hospitals. The mean concentrations of estrone and estradiol in malignant breast tumors obtained in the three loca-

Table 2: Mean Endogenous Concentrations of Estrone and Estradiol in Human Breast Tissues Collected in Countries with Different Incidence.

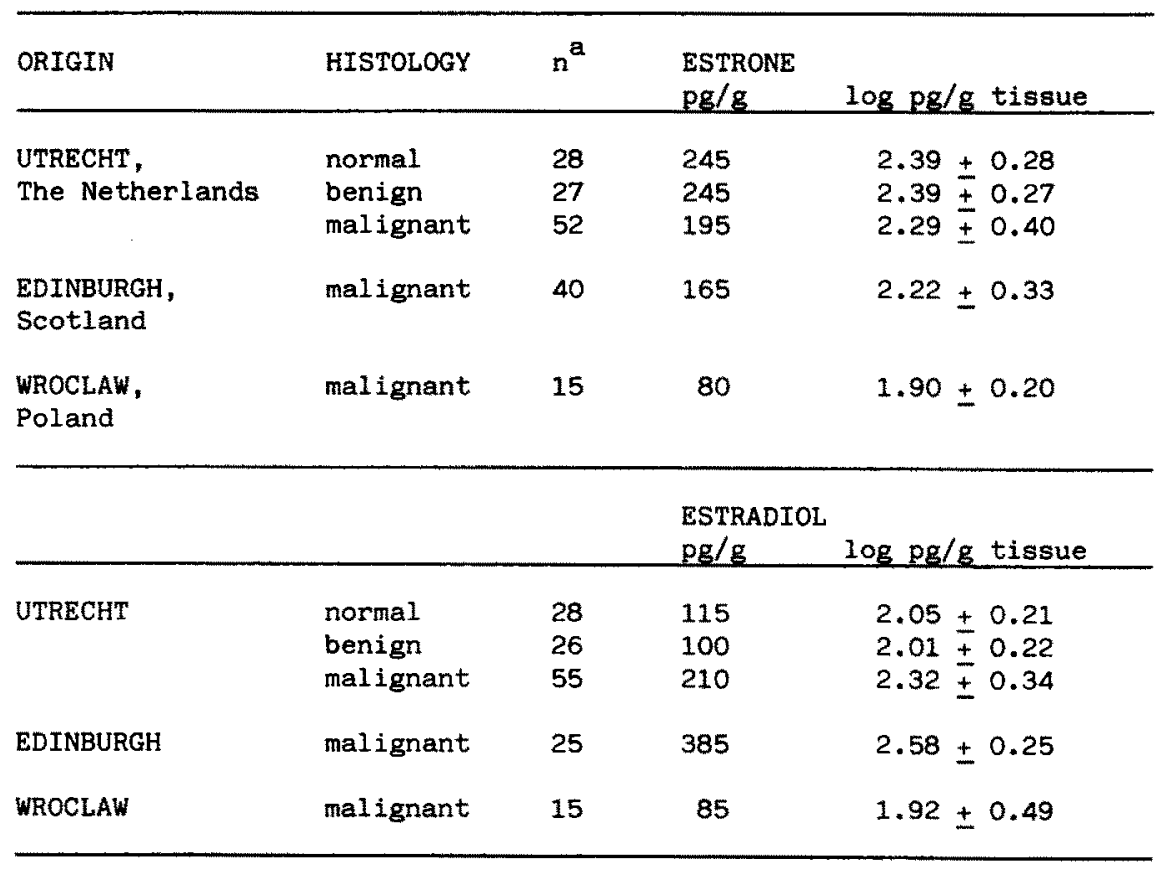

$a_{n}$, number of samples studied. 
tions, which have differences in incidence and natural history of the disease, are given in Table 2. As the menopausal status was not available in all individual subjects, data for all patients, premenopausal as well as postmenopausal, have been combined. In the population of Utrecht, no differences in estradiol levels had been found between the two age groups; since the levels were very similar (see Table 1).

Although an appreciable variation was seen in each of the three groups with a malignant tumor, the differences in the estradiol concentrations were statistically highly significant. Scottish women had the highest intratissue estradiol concentrations, the Dutch population was lower, whereas the Polish women had clearly the lowest levels. In the last group estrone levels also were lower, the two other groups had comparable estrone concentrations. Plasma levels were not available in all individual women; however, Polish postmenopausal women showed estrogen plasma concentrations similar to those of Dutch women.

These preliminary data suggest differences in the intratissue levels of estrogens in breast tumors that are related to the natural history of the disease. It is completely unclear at present why these differences were observed.

Analysis of both estrogens in non-breast fat tissue in Polish women showed estrone levels similar to those in breast tumors (mean value $170 \mathrm{pg} / \mathrm{g}$ tissue) and a very low estradiol concentration (mean level 45 $\mathrm{pg} / \mathrm{g}$ tissue). This finding points to the fact that local estradiol production in breast tissues must play a role, possibly independent of aromatase activity.

For a better understanding of the meaning of our preliminary observations, a number of studies remain to be done. Estrogen levels in normal breast tissue obtained from different countries and their 
relation to receptors have to be studied. Although the intratissue estrogen concentrations suggest a relation with the incidence of the disease in that country, a relation with the course of the disease in any individual is still unknown.

Because the absolute concentrations of estrogens seem to differ between countries and the ratio between estrone and estradiol is not constant, aromatase activity alone is unlikely to be able to explain the differences observed. Additional factors, such as activity of the 17-hydroxysteroid dehydrogenase and/or more or less specific binding proteins, must be taken into account. Their roles remain to be established.

\section{REFERENCES}

1. Poortman $J(1980)$. Role of steroid hormones in the genesis of human mammary cancer. Reviews on Endocrine Related Cancers. 6:27-33.

2. Judd HL, Davidson BJ, Frumar AM, Shamonski IM, Lagasse LD, and Ballon SC (1976). Serum androgens and estrogens in postmenopausal women with and without endometrial cancer. AM J OBSTET GYNECOL 136: 859-866.

3. Fishman J, Fukushima D, O'Connor J, Rosenfeld RS, Lynch HT, and Lynch JF (1978). Plasma hormone profiles of young women at risk for familial breast cancer. CANCER RES 38:4006-4011.

4. Dao $T$ (1979). Metabolism of estrogens in breast cancer. BIOCHIM BIOPHYS ACTA 560:397-426.

5. Moore JW, Clark CMG, Bulbrook RD, Hayward JL, Murai JT, Hammond GL, and siiteri PK (1982). Serum concentrations of total and nonproteinbound oestradiol in patients with breast cancer and normal controls. INT J CANCER 29:17-21.

6. MacDonald PC, Edman $C \bar{D}$, Hemsell DL, Porter JC, and Silterf PK (1978). Effect of obesity on conversion of plasma androstenedione to estrone in postmenopausal women with and without endometrial cancer. AM J OBSTET GYNECOL 130:448-455.

7. Guerrero $R$, Landgren $B M$, Montiel $R$, Cekan $Z$, and Diczfalusy $E$ (1975). Unconjugated steroids in the human endometrium. CONTRACEPTION 11:169-77.

8. Batra 5 , Grundse11 $\mathrm{H}$, and Sjoberg NO (1977). Estradiol and progesterone concentrations in human endometrium during the menstrual. cycle. CONTRACEPTION 16:217-224.

9. Alsbach GPJ, Franck $\overline{E R}$, Poortman J, and Thijssen JHH (1983). Subcellular distribution of estradiol and estrone in human endometrium and myometrium during the menstrual cycle. CONTRACEPTION 27:409421 . 
10. Vermeulen-Meiners C, Benedek Jaszmann LJ, Haspels AA, Poortman J, and Thijssen JHH (1984). The endogenous concentration of estradiol and estrone in normal human postmenopausal endometrium. J STEROID BIOCHEM 21:607-612.

11. Van Landeghem AAJ, Poortman J, Nabuurs M, and Thijssen JHH (1985). Endogenous concentration and subcellular distribution of estrogens in normal and malignant human breast tissue. CANCER RES 45:29002906.

12. Tseng $L$ and Gurpide $E$ (1972). Nuclear concentration of estradiol in superfused slices of human endometrium. AM J OBSTET GYNECOL 114: 995-1001.

13. Abul Hajj Y (1979). Relationship between estrogen receptors, 17 hydroxysteroid dehydrogenase and estrogen content in human breast cancer. STEROIDS $34: 217-225$.

14.Edery M, Goussard J, Dehennin M, Scholler J, Reiffsteck J, and Drosdowski M (1981). Endogenous estradiol-17/ $\beta$ concentration in breast tumours determined by mass fragmentography and by radioimmunoassay: relationship to receptor content. EUR J CANCER 17:115120.

15.Fishman $J$, Nisselbaum JS, Menedez-Botet CJ, and Schwartz MK (1977). Estrone and estradiol content in human breast tumours: relationship to estradiol receptors. J STEROID BIOCHEM 8:893-896.

16. Wiegerinck MAHM, Poortman J, Donker TH, and Thijssen JHH (1983). In vivo uptake and subcellular distribution of tritium labeled estrogens in human endometrium, myometrium and vagina. J CLIN ENDOCRINOL METAB 56:76-86.

17. Abul Hajj $Y$, Iverson $R$, and Kiang DT (1979). Aromatization of androgens by human breast cancer. STEROIDS 33:205-222.

18. Griffiths $\mathrm{K}$, Jones D, Cameron EHD, Gleave EN, and Forrest APM. Transformation of steroids by mammary cancer tissue. In: Estrogen Target Tissues and Neoplasia (Dao T, ed), Chicago University Press, chicago (1972), pp 151-162.

19. Li $\mathrm{K}$ and Adams JB (1981). Aromatization of testosterone and oestrogen receptor levels in human breast cancer. J STEROID BIOCHEM $14: 269-272$.

20. Miller WR, llawkins RA, and Forrest APM (1982). Significance of aromatase activity in human breast cancer. CANCER RES, SUPPL 42: 3365-3368.

21.Perel E, Davis $S$, and Killinger D (1981). Androgen metabolism in male and female breast tissue. STEROIDS 37:345-352.

22. Varela RM, and Dao T (1978). Estrogen synthesis and estradiol binding by human mammary tumours. CANCER RES 38:2429-2433.

23.King WJ and Greene GL (1984). Monoclonal antibodies localise oestrogen receptor in the nuclei of target cells. NATURE 307:745747.

24. Welshons WV, Lieberman ME, and Gorski J (1984). Nuclear localisation of unoccupied oestrogen receptors. NATURE 307:747-749.

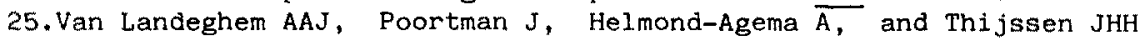
(1984). Measurement of endogenous subcellular concentrations of steroids in tissue. J STEROID BIOCHEM 20:639-644.

26.Vermeulen-Meiners $C$, Poortman $J$, Haspeis AA, and Thijssen JHH (1986). The endogenous concentration of estradiol and estrone in pathological human postmenopausal endometrium. J STEROID BIOCHEM 24:1073-1078. 